\title{
Research on Innovation and Entrepreneurship Education in the Context of Big Data
}

\author{
Zhu Wei \\ Xidian University, Xi'an, Shaanxi, China, 710126
}

Keywords: big data; innovation and entrepreneurship education; countermeasures

\begin{abstract}
With the rapid development of Internet technology, a large amount of information is flooded on the Internet. How to combine the current big data background and create the innovation and entrepreneurship education which is in line with the current social background has become a problem that needs to be solved urgently. In the context of big data, this paper aims to overcome education mode reform in order to overcome the traditional innovation and entrepreneurship education. This paper mainly studies innovation and entrepreneurship database model from the establishment of big data, and then discusses the changes brought about by big data. In this paper, several countermeasures are proposed to promote innovation and entrepreneurship education in the context of big data, including promoting education informatization, building a big data service platform, attaching importance to information technology, and cultivating innovative talents.
\end{abstract}

\section{Introduction}

In 2015, China issued the policy on deepening the implementation of education reform of innovation and entrepreneurship in institutions of higher learning. The "opinion" advocates further integration of China's economy and information technology, and designates the direction of innovation and entrepreneurship education. With the rapid development of Internet technology, a large amount of information is flooded on the Internet, and the big data environment comes with it. Data support has become a necessity for the development of all industries. In the modern society, the use of data for demonstration, explanation, decision-making has become the main way. It can be said that the data culture formed in the context of big data is affecting us all the time. However, the innovation and entrepreneurship of college students cannot be separated from market research and data analysis. Therefore, how to combine with big data has become an important trend in the future development of education activities in Chinese universities. This article is based on the current big data, carry out innovation and entrepreneurship education research.

\section{Application Framework and Application Content of Big Data in Innovation and Entrepreneurship Education}

\subsection{Application framework of big data in innovation and entrepreneurship education.}

In this paper, cloud computing is deeply integrated with big data mining technology. We integrate various information related to innovation and entrepreneurship into the database source, and establish real-time dynamic innovation and entrepreneurship education database (Figure 1). This database can provide various innovative and entrepreneurial services for Chinese universities or innovation and entrepreneurship education institutions, such as innovation and entrepreneurship information, national and local government preferential policies, etc. According to functions, it can be divided into data support layer, cloud computing service platform and application service system layer.

\subsection{The application content of big data in innovation and entrepreneurship education}

In this paper, the database is mainly supported by big data, and the automatic collection and processing of data information is realized by cloud computing and big data mining technology. 
Through the data information database and the big data platform to connect with each university data terminal, perfect the information of the current database (Figure 2). Through cloud computing, the automatic collection, storage, mining and analysis of innovation and entrepreneurship data are completed, which provides real and effective information for education of Chinese universities.

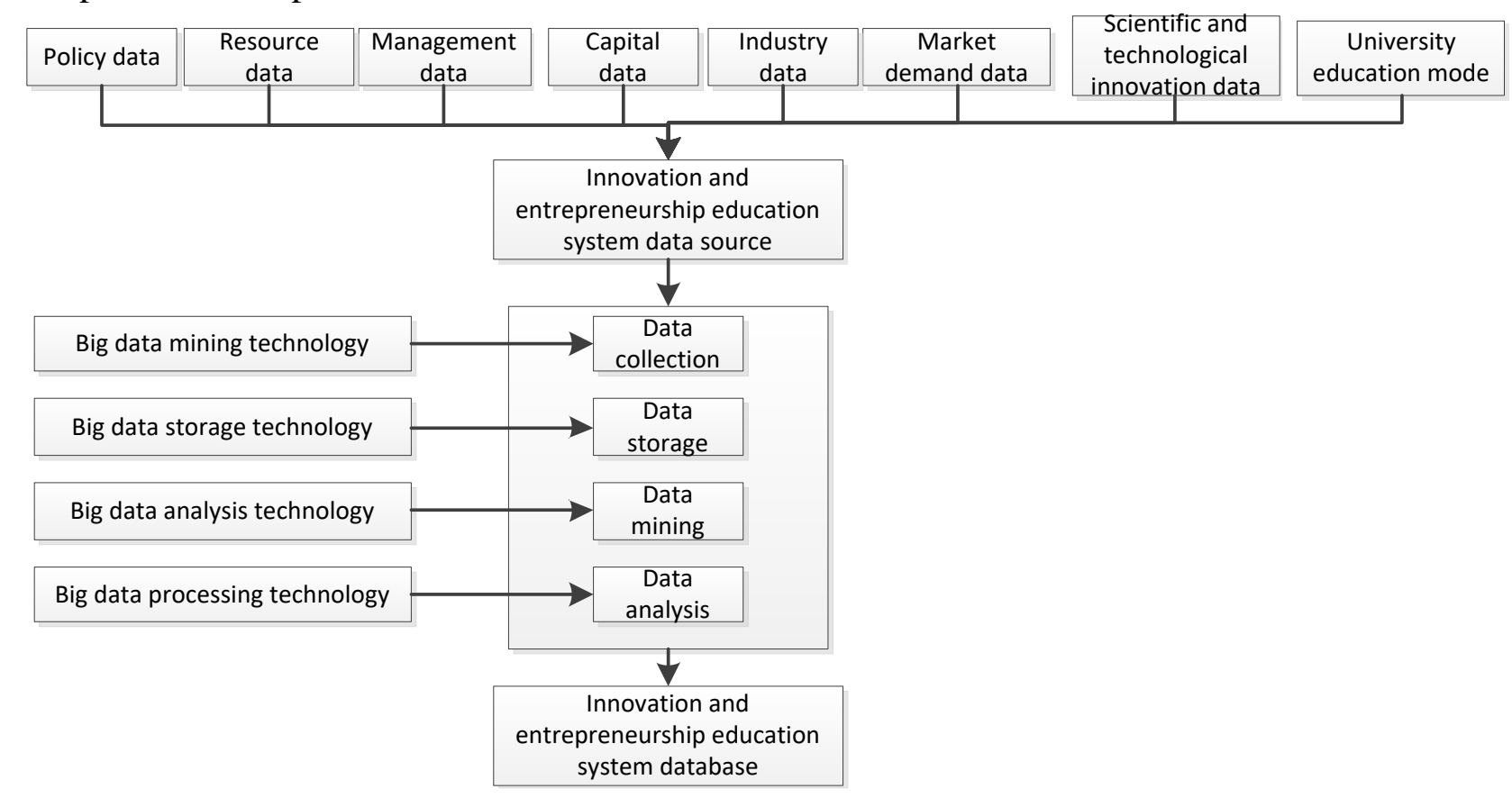

Figure 1. Innovation and entrepreneurship education application framework based on big data

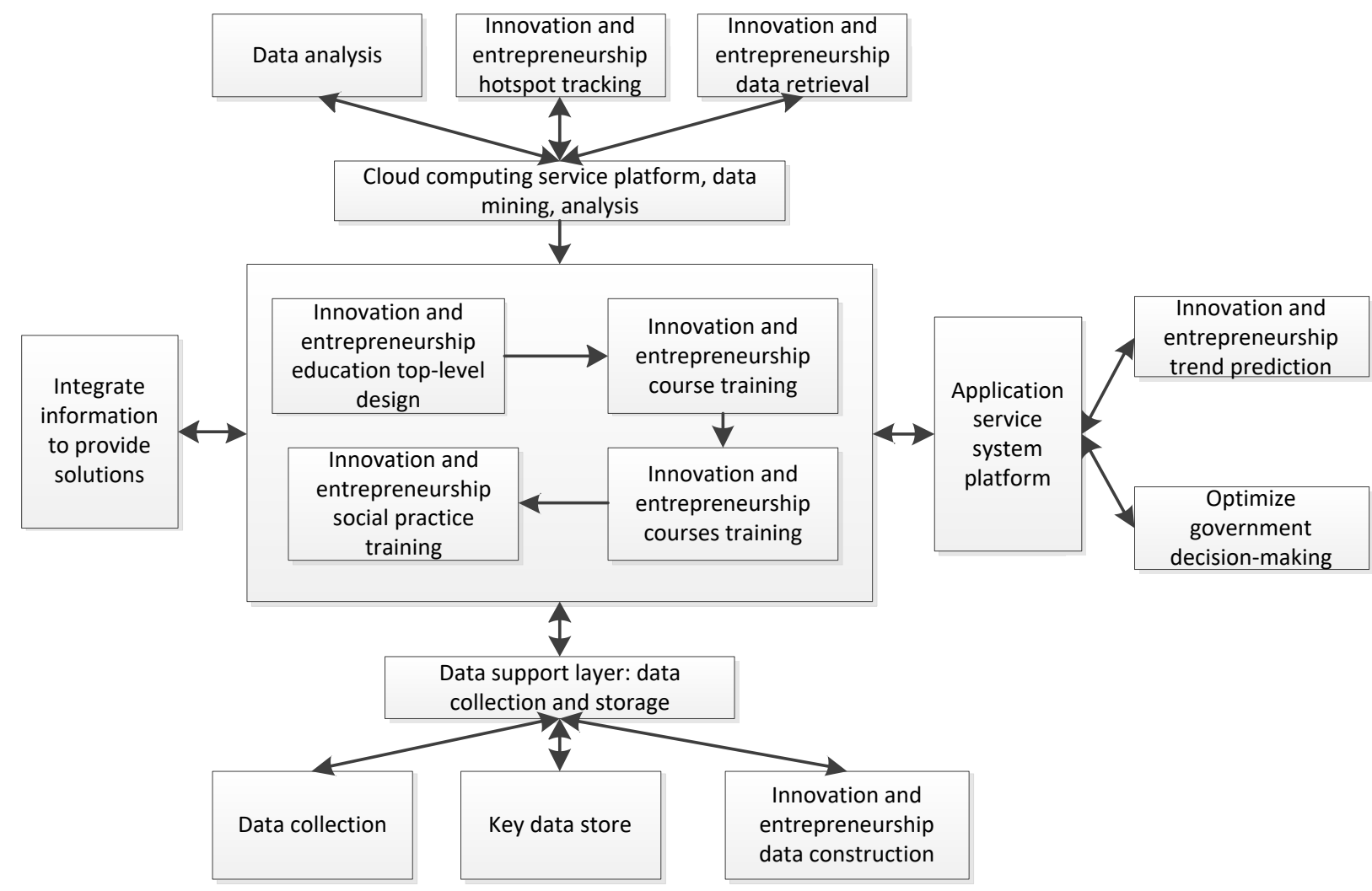

Figure 2. Innovation and entrepreneurship education application content based on big data

\section{Promotion Strategy of Innovation and Entrepreneurship Education Based on Big Data}

\subsection{Promote education informatization and build a big data service platform.}

Based on the innovation of the era to support entrepreneurship education needs a lot of data, and 
these data are invalid information, which would require the use of all kinds of information to make use of data mining technology to deal with. Therefore, colleges and universities should promote education informatization and complete the training of students through the service platform of big data.

Colleges and universities should attach importance to the building and utilization of big data platforms, and adopt big data analysis technology to help managers better improve education. Chinese universities promote innovation and entrepreneurship by integrating information system. And by building a large data service platform to connect directly with the big data database, the education resources will be established in China. Through the construction of a big data platform for innovation and entrepreneurship, universities can directly investigate the innovation and entrepreneurship information and data through a large database. Through innovation and entrepreneurship, college students can predict the future innovation and entrepreneurship with great help.

\subsection{Use data to speak and innovate teaching mode.}

As big data technology has been applied to China's education industry, Chinese universities have instilled in students a way of thinking about problems with data. Through this kind of intuitive understanding to carry on the teaching and the work, this kind of innovative teaching mode is accepted by the college students gradually. Big data technology has become the main form and tool of teaching in colleges and universities. As a result, Chinese universities must use big databases to explain problems when they innovate and start business education. Compared with the traditional teacher-centered teaching mode, this innovative teaching mode will greatly develop students' thinking. The new education model of "Internet + education" can flexibly develop students' intelligence and level, so as to help students to achieve the best results. China's management of colleges and universities should comply with the development of The Times, by enhancing the students consciousness of big data, improve the students' ability of data processing and analysis, to cultivate college students' way of thinking "speaking with data. This new teaching mode will definitely reshape the school's teaching system, thus improving the education quality of Chinese universities as a whole.

\section{Conclusion}

As a tool, big data should adapt to the trend of education informationization and change the present situation of education in a more efficient way. In addition to studying traditional courses, college students in the era of big data need to be good at exploiting and absorbing useful information on the Internet platform to improve their self-knowledge. In the vast amount of information, the garbage information is removed and the innovation points are found to be keen to avoid blind detour and increase the success rate of the real startup road in the future. The use of big data is far from universal, and far from the magic of imagination. The application of big data in innovation and entrepreneurship education is still in the exploration stage. From the design of the system to the analysis model, there are still many problems to be solved and improved.

\section{References}

[1] Anshari, Muhammad; Alas, Yabit; Guan, Lim Sei . Developing Online Learning Resources: Big Data, Social Networks, and Cloud Computing to Support Pervasive Knowledge. Education and Information Technologies (2016), p. 1663 - 1677

[2] Benner Mate. The Scandinavian Challenge The future of Advanced Welfare States in the Knowledge Economy. Acta Sociological (2013), p. 46-48.

[3] Bruce Schneier. Data and Goliath: The Hidden Battles to Collect Your D-ata and Control Your World. W. W. Norton (2015), p. 215-217

[4] Borthwick, Arlene C.; Anderson, Cindy L.; Finsness, Elizabeth S.; Foulger, Teresa S. Special 
Article Personal Wearable Technologies in Education: Value or Villain. Journal of Digital Learning in Teacher Education (2015), p. 85-92

[5] Low MB, MacMillanI C. Entrepreneurship: Past Research and Future Challenges. Journal of Management (2008), p. 139-161

[6] Shane B, Venkataraman S. The Promise of Entrepreneurship as a Field ofResearch. Academy of Management Review (2010), p. 217-226

[7] Seibert SE, Kraimer, ML, Liden RC. A Social Capital Theory of Career Success. Academyof Management Journal (2011), p. 219-237 